\title{
Method for Designing Alarm System Using DAEs, CE Matrices, and Preference Indices
}

\author{
Takashi Hamaguchi ${ }^{1}$, Hiroto Sakashita ${ }^{1}$, Hiroki Moritani ${ }^{1}$, \\ Kazuhiro TAKedA ${ }^{2}$, Naoki KImURA ${ }^{3}$ and Masaru NodA ${ }^{4}$ \\ ${ }^{1}$ Graduate School of Engineering, Nagoya Institute of Technology, Gokiso-cho, Showa-ku, Nagoya-shi, \\ Aichi 466-8555, Japan \\ ${ }^{2}$ Graduate School of Engineering, Shizuoka University, 3-5-1 Johoku Hamamatsu-shi, Shizuoka 432-8561, \\ Japan \\ ${ }^{3}$ Faculty of Engineering, Kyushu University, 744 Motooka, Nishi-ku, Fukuoka-shi, Fukuoka 819-0395, \\ Japan \\ ${ }^{4}$ Department of Chemical Engineering, Fukuoka University, 8-19-1 Nanakuma, Jonan-ku, Fukuoka-shi, \\ Fukuoka 814-0180, Japan
}

Keywords: Alarm System Design, Alarm Management, Differential Algebraic Equations, CE Matrices, Preference Indices

\begin{abstract}
A plant alarm system provides critical information to operators as the third layer of independent protection layers when a chemical plant is undergoing an abnormal situation. Therefore, methods for designing plant alarm systems are crucial for plant safety. Because plants are maintained as part of the plant lifecycle, plant alarm systems should be properly managed and adapted to changes that occur throughout the lifecycle. To manage changes, the design rationale of the plant alarm system should be explained explicitly. In the present paper, we explain a design problem for plant alarm systems and propose a method for designing alarm systems by using differential and algebraic equations, cause-effect matrices, and preference indices.
\end{abstract}

\section{Introduction}

In most chemical plants, distributed control systems (DCSs) are installed to simultaneously control thousands of process variables. The main role of operators is to supervise operations to keep plants safe by using process alarms in both normal and abnormal situations. The DCS is an effective means of decreasing the operators' load in normal situations, and the number of operators has recently decreased due to the introduction of advanced control systems. Although the frequency of accidents is very low, the load of operators in abnormal situations has become heavier. Operators face difficult tasks including complex decision making for detection, diagnosis, assessment of urgency, and countermeasure planning in managing abnormal situations. Moreover, the DCS is not effective in abnormal situations because it lacks diagnosis systems or decision-support systems for preventing accidents or disasters. The alarm system becomes more and more important to maintain safe plant operation. Progress of the DCS has made it possible to install many alarms inexpensively. While suitably designed alarm systems can support operators, poorly designed

Received on December 6, 2016; accepted on May 9, 2017 DOI: 10.1252 jcej.16we365

Partly presented at the 7th International Symposium on Design, Operation and Control of Chemical Processes (PSE Asia), Tokyo, July 2016 Correspondence concerning this article should be addressed to $\mathrm{T}$. Hamaguchi (E-mail address: hamaguchi.takashi@nitech.ac.jp). ones might disrupt operators by alarm floods and nuisance alarms. Therefore, alarm system design must be considered seriously for safe plant operation.

\section{IPLs and Alarm Management Lifecycle}

To support safe plant operations, the use of independent protection layers (IPLs) has been proposed (CCPS, 1993). A plant alarm system performs a very important role in the initial response to prevent accidents or disasters as the third layer of the IPLs. A plant alarm system consisting of critical alarms must provide useful information to operators. In most cases, alarms lead to confusion as it is not clear whether an alarm is indicating an announcement, alert, caution, or warning. In the present paper, we focus on such critical alarms to design suitable alarm systems.

An alarm system also needs to be properly managed throughout the plant lifecycle because plant modifications regularly occur. A framework and first alarm for managing the alarm system lifecycle was previously proposed (International Society of Automation, 2009), and a revised illustration was proposed in IEC 62682 (IEC, 2014). We focus on "Identification" and "Rationalization" in the alarm management lifecycle (AMLC) in IEC 62682. The AMLC contains three loops: a monitoring and maintenance loop, a monitoring and management of change loop, and an audit of philosophy loop. One problem with designing plant alarm systems is how to design, construct, operate, and maintain plant alarm systems properly throughout the plant lifecycle. For 
example, it is assumed that some alarms are designed based on an existing safety system such as safety valve. However, if the safety valve cannot be used for some reason, the alarms must be modified in this situation. To solve this problem, the design rationale of the plant alarm system should be explained explicitly. Whenever a plant is modified, the plant model must be updated on the basis of the design rationale.

To diagnose system failures in the chemical process, Iri et al. (1979) and Shiozaki et al. (1985) showed the application of a cause-effect (CE) graph and its effectiveness. For designing a logical and systematic alarm system, we previously proposed a sensor selection method that uses a CE graph (Takeda et al., 2010). In this method, a plant CE matrix $\boldsymbol{G}$ is generated by using a CE graph of the plant on the basis of the directed graph expression of cause-effect relationships among process variables, manipulated variables, and fault origins. A preference index based on reachability matrix $\boldsymbol{R}$, which is based on CE matrix $\boldsymbol{G}$, can be used to select alarm source variable candidates.

However, it is difficult to keep consistency in the generation and management of the CE graph of a plant because the interpretation of cause-effect relationships among process variables, manipulated variables, and fault origins may vary depending on the user. Hamaguchi and co-authors proposed a hierarchical CE model and modularized CE model for designing alarm systems (Hamaguchi et al., 2012, 2013; Takeda et al., 2014). However, these models are not enough to solve this problem. To help manage changes in a plant model, a support system for generating and managing the model with consistency is required.

We previously proposed a method for generating and checking alarm configurations using CE matrices (Hamaguchi et al., 2015). For this method, we introduced an alarm configuration matrix $\boldsymbol{A}$, alarm loop model $\boldsymbol{G A}$, and reachability matrix $\boldsymbol{R}$ for generating and checking alarm configurations. Although the method was useful for rejecting bad alarm configurations, more information is needed to select better alarm configurations. A method was proposed for generating a plant CE matrix based on differential and algebraic equations (DAEs) for a plant-wide control loop configuration design tool (Kojima et al., 2014) and for dividing the zones of a process control network to improve cyber security (Moritani et al., 2014). Moritani et al. (2016) proposed a method of generating fault trees for ICS safety and security by using DAEs. A fault tree is a useful tool for process hazard analysis (PHA). Therefore, DAEs can be used as the basis of the design of an operator support system, considering the management of change throughout the plant life cycle.

To develop a support system for generating and managing a plant model with consistency for alarm system design, we applied a DAE method of modeling a plant model for alarm system design. Moreover, we modified the controller configuration method based on CE matrices for systematic alarm system design.

\section{Problem with Designing Alarm Systems}

An alarm system should be properly managed throughout the plant lifecycle. To properly manage a system, the activities concerning the system and information flows between the activities during the plant lifecycle should be explicitly expressed. Furthermore, "constraints," "inputs," and "outputs" of each activity and information flow in the form of a business process model (BPM) have been proposed. Takeda et al. (2015a, 2015b) proposed an alarm management business process model (AMBPM) and derived business flows. A part of an activity tree of the AMBPM concerning the alarm system design process is shown in Figure $\mathbf{1}$ because the whole AMBPM is very large. Important activities corresponding to alarm system design are filled in with yellow.

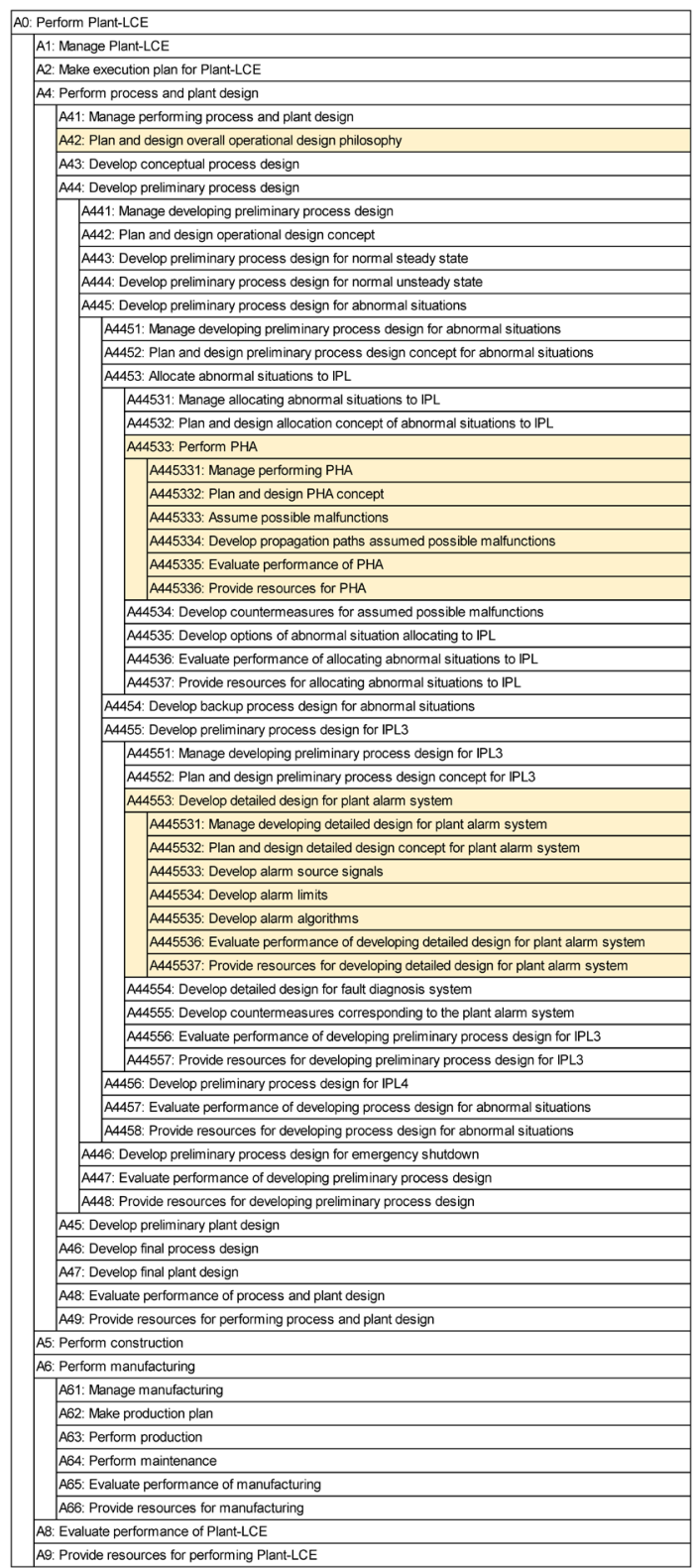

Fig. 1 Part of activity tree of AMBPM concerning alarm system design process 
A42, "Plan and design overall operational design philosophy," is applied to the basis of alarm system design. One of the core activities of the alarm system design process of the AMBPM is A44533, "Perform PHA." The key information of alarm system design, such as the information required for operators and the reasons that such information is required, must be gained from the PHA. Another core activity of the alarm system design process of the AMBPM is A44553, "Develop detailed design for plant alarm system." For this activity, another activity, A445533, "Develop alarm source signals," selects or newly designs alarm source signals. This paper corresponds to this activity. Assume that suitable countermeasures must be prepared for accidents. A countermeasure may be suitable for one accident, but it might be worse for another accident. Therefore, assumed accidents must be grouped in terms of effective countermeasures, and an alarm must be useful to distinguish them. The alarm system must be considered systematically. A detailed design such as of the threshold of the alarm and filtering corresponds to A445534 and A445535. These activities are out of the scope of the present study.

The purpose of an alarm must be considered to design an alarm system. In the present paper, we consider that alarms can be divided into two modes for critical accidents identified by PHA because suitable countermeasures might differ depending on the mode. Mode 1 is for detecting the occurrence of fault origins before the effects of the origins reach each condition for accidents. Mode 2 is for detecting the occurrence of each condition for accidents. For example, there are two fault origins and two fault trees, as shown in Figure 2. Accident 1 of fault tree 1 has arisen from abnormal values of nodes 6 and 7 . Accident 2 of fault tree 2 has arisen from abnormal values of nodes 7 and 8 . The propagation is based on the CE model. Fault origins 1 and 2 can cause the values of nodes 1 and 2 to be abnormal, respectively. The effect of fault origin 1 can reach node 6 via node 3 . The effect of fault origin 2 can reach nodes 7 and 8 via nodes 4 and 5 . If fault origin 2 occurs, then accident 2 might arise from only the effect of fault origin 2, but accident 1 does not arise because the effect cannot reach node 6 . In this example, the yellow zone is mode 1 , and the blue zone is mode 2 , as shown in Figure 2. The difference in suitable countermeasures, allowances, and so on must be considered for generating and



Fig. 2 Fault origins, fault trees, and modes checking alarm configurations. However, an algorithm for generating and checking the configurations can be used for both modes. The CE model might change for abnormal situations. If the liquid level decreases in a reactor and a cooling pipe does not contact the liquid, then the cooling water flow rate cannot affect the temperature of the liquid. Therefore, the CE model can generate configurations systematically for various situations with consistency.

Let $M$ be a set of all measured variables that can be used for alarm source variables, process variables, and manipulated variables on a DCS. Let $\mathrm{C}$ be a set of fault origins to be distinguished by use of the alarm system. Therefore, $\mathrm{C}$ is a subset of all assumed fault origins in a plant. We assume that $\mathrm{C}$ can be given by PHA, such as the fault tree, HAZard and Operability (HAZOP) study and so on. In the present paper, we define the alarm system design problem as how to select alarm source variables from $\mathrm{M}$ to distinguish each fault origin of C.

\section{Basic Method for Alarm System Design Using DAEs, CE Matrices, and Preference Index}

\subsection{Example plant and DAEs}

An example plant and Eqs. (1)-(5) as DAEs are shown in Figure 3. In this example, the boundary conditions are given as system outside pressure $P_{1}$ and $P_{2}$ and atmospheric pressure $P_{0}$. The inlet flow rates $F_{1}$ and $F_{2}$ and the outlet flow rate $F_{3}$ are determined in accordance with the valve openings $V_{1}$, $V_{2}$, and $V_{3}$. The tank level, cross-sectional area, and bottom pressure are respectively $L_{1}, S_{1}$, and $P_{3}$. The others, $\alpha, k_{1}, k_{2}$, and $k_{3}$, are proportionality constants. In this example, $V_{1}$ and $V_{3}$ are assumed to be elements of $\mathrm{C}$, and $F_{1}$ and $F_{3}$ are assumed to be elements of $\mathrm{M}$.

\subsection{Generation of plant CE matrix $\mathbf{G}$ from DAEs}

Step 1: The matrix in Table $\mathbf{1}$ is generated from the DAEs in Figure 3. The rows in the matrix correspond to the equations. The columns correspond to variables in the DAEs. $x$, $u$, and $z$, respectively, mean state variables in the differential equations, input variables, and variables determined by algebraic equations. This method is based on Kojima et al. (2014). In the present paper, we divide the $z$ into measured $\left(F_{1}\right.$ and $\left.F_{3}\right)$ and unmeasured $\left(F_{2}\right.$ and $\left.P_{3}\right)$ variables, as shown in Table 1. Element " 1 " in the matrix means the entry of the variables in the equations, while a blank element indicates “0” elements.

Step 2: In Eq. (5), to explain the differential pressure

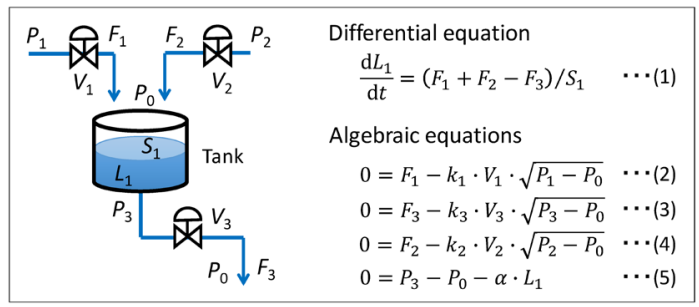

Fig. 3 Example plant and DAEs 
Table 1 Step 1 for generating $\boldsymbol{G}$

\begin{tabular}{|c|c|c|c|c|c|c|c|c|c|c|c|c|}
\hline & \multicolumn{2}{|c|}{$\begin{array}{l}\text { Stata variables } \\
\text { in differential } \\
\text { equations }\end{array}$} & \multirow{2}{*}{\multicolumn{4}{|c|}{$\begin{array}{c}\begin{array}{c}\text { Variables determined } \\
\text { by algebraic equations }\end{array} \\
z(t)\end{array}$}} & \multicolumn{6}{|c|}{ Input variables } \\
\hline & \multirow{3}{*}{$\begin{array}{l}d x / d t \\
d L_{1} / d t\end{array}$} & \multirow{3}{*}{$\begin{array}{l}x(t) \\
L_{1}\end{array}$} & & & & & \multicolumn{6}{|c|}{$u(t)$} \\
\hline & & & \multicolumn{2}{|c|}{$\begin{array}{l}\text { Measured } \\
\text { variables }\end{array}$} & \multicolumn{2}{|c|}{\begin{tabular}{|l|} 
Unmeasured \\
variables
\end{tabular}} & \multirow[b]{2}{*}{$v_{1}$} & \multirow[b]{2}{*}{$v_{2}$} & \multirow[b]{2}{*}{$v_{3}$} & \multirow[b]{2}{*}{$P_{1}$} & \multirow[b]{2}{*}{$P_{2}$} & \multirow[b]{2}{*}{$P_{0}$} \\
\hline & & & $F_{1}$ & $F_{3}$ & $F_{2}$ & $P_{3}$ & & & & & & \\
\hline (1) & 1 & & 1 & 1 & 1 & & & & & & & \\
\hline (2) & & & 1 & & & & 1 & & & 1 & & 1 \\
\hline (3) & & & & 1 & & 1 & & & 1 & & & 1 \\
\hline (4) & & & & & 1 & & & 1 & & & 1 & 1 \\
\hline (5) & & 1 & & & & 1 & & & & & & 1 \\
\hline
\end{tabular}

Table 2 Step 2 for generating $\boldsymbol{G}$

\begin{tabular}{|c|c|c|c|c|c|c|c|c|c|c|c|c|}
\hline & $\mathrm{d} x / \mathrm{d} t$ & $x(t)$ & \multicolumn{4}{|c|}{$z(t)$} & \multicolumn{6}{|c|}{$u(t)$} \\
\hline & $\mathrm{d} L_{1} / \mathrm{d} t$ & $L_{1}$ & $F_{1}$ & $F_{3}$ & $F_{2}$ & $P_{3}$ & $v_{1}$ & $v_{2}$ & $v_{3}$ & $P_{1}$ & $P_{2}$ & $P_{0}$ \\
\hline (1) & 1 & & 1 & -1 & 1 & & & & & & & \\
\hline (2) & & & 1 & & & & 1 & & & 1 & & -1 \\
\hline (3) & & & & 1 & & 1 & & & $\overline{11}$ & & & -1 \\
\hline (4) & & & & & 1 & & & 1 & & & 1 & -1 \\
\hline (5) & & 1 & & & & 1 & & & & & & -1 \\
\hline
\end{tabular}

Table 3 Step 3 for generating $\mathbf{G}$

\begin{tabular}{|c|c|c|c|c||c|c|c|c|c|c|c|c|}
\cline { 2 - 13 } \multicolumn{1}{c|}{} & $\mathrm{d} x / \mathrm{d} t$ & \multicolumn{1}{c|}{$x(t)$} & \multicolumn{5}{c|}{$z(t)$} & \multicolumn{6}{c|}{$u(t)$} \\
\cline { 2 - 13 } \multicolumn{1}{c|}{} & $\mathrm{d} L_{1} / \mathrm{d} t$ & $L_{1}$ & $F_{1}$ & $F_{3}$ & $F_{2}$ & $P_{3}$ & $V_{1}$ & $V_{2}$ & $V_{3}$ & $P_{1}$ & $P_{2}$ & $P_{0}$ \\
\hline$(1)$ & 1.722 & & 1 & -1 & 1 & & & & & & & \\
\hline$(2)$ & & & 1.859 & & & & 0.690 & & & 1 & & -1 \\
\hline$(3)$ & & & & 1.870 & & 1 & & & 1.449 & & & -1 \\
\hline$(4)$ & & & & & 0.646 & & & 0.918 & & & 1 & -1 \\
\hline$(5)$ & & 1.320 & & & & 1 & & & & & & -1 \\
\hline
\end{tabular}

Table 4 Step 4 for generating $\boldsymbol{G}$

\begin{tabular}{|c|c|c|c|c|c|c|c|c|c|c|c|}
\hline & $\mathrm{d} x / \mathrm{d} t$ & $x(t)$ & \multicolumn{4}{|c|}{$z(t)$} & \multicolumn{5}{|c|}{$u(t)$} \\
\hline & $\mathrm{d} L_{1} / \mathrm{d} t$ & $L_{1}$ & $F_{1}$ & $F_{3}$ & $F_{2}$ & \multicolumn{2}{|c|}{ Inverse matrix } & $v_{3}$ & $P_{1}$ & $P_{2}$ & $P_{0}$ \\
\hline (1) & 1.722 & & 1 & -1 & 1 & 1.548 & 0 & & & & \\
\hline (2) & & & 1.859 & & & 0 & 1 & & 1 & & -1 \\
\hline (3) & & & & 1.870 & & & & 1.449 & & & -1 \\
\hline (4) & & & & & 0.646 & & 0.918 & & & 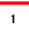 & -1 \\
\hline (5) & & 1.320 & & & & 1 & & & & & -1 \\
\hline
\end{tabular}

$P_{3}-P_{0}$, the relationship is expressed in Table 1. Therefore, the element of $P_{0}$ is modified from " 1 " to " -1 ." The relationship is boxed off, as shown in Table 2. In the same way, the elements of $F_{3}$ in Eq. (1) and $P_{0}$ in Eqs. (2)-(4) are modified from " 1 " to " -1 ."

Step 3: The rest of the variables are assigned positive random numbers, as shown in Table 3. The random numbers should not be integers; otherwise, unexpected elements may be swept out in Step 5.

Step 4: For Step 5, the inverse matrix of $F_{2}$ and $P_{3}$ of Eqs. (4) and (5) is generated, as shown in Table 4.

Step 5: The generated inverse matrix is multiplied by the
Table 5 Step 5 for generating $\boldsymbol{G}$

\begin{tabular}{|c|c|c|c|c|c|c|c|c|c|c|c|c|}
\hline & $\mathrm{d} x / \mathrm{d} t$ & $x(t)$ & \multicolumn{4}{|c|}{$z(t)$} & \multicolumn{6}{|c|}{$u(t)$} \\
\hline & $\mathrm{d} L_{1} / \mathrm{d} t$ & $L_{1}$ & $F_{1}$ & $F_{3}$ & $F_{2}$ & $P_{3}$ & $v_{1}$ & $v_{2}$ & $v_{3}$ & $P_{1}$ & $P_{2}$ & $P_{0}$ \\
\hline (1) & 1.722 & & 1 & -1 & (1) & & & & & & & \\
\hline (2) & & & 1.859 & & 1 & & 0.890 & & & 1 & & -1 \\
\hline (3) & & & & 1.870 & & & & & 1.449 & & & -1 \\
\hline$(4)^{\prime}$ & & & & & & & & 1.421 & & & 1.548 & -1.548 \\
\hline${ }^{(5)^{\prime}}$ & & 1.320 & & & & & & & & & & -1 \\
\hline
\end{tabular}

Table 6 Result of Step 5

\begin{tabular}{|c|c|c|c|c|c|c|c|c|c|c|c|c|}
\hline & $d x / d t$ & $x(t)$ & \multicolumn{4}{|c|}{$z(t)$} & \multicolumn{6}{|c|}{$u(t)$} \\
\hline & $\mathrm{d} L_{1} / \mathrm{d} t$ & $L_{1}$ & $F_{1}$ & $F_{3}$ & $F_{2}$ & $P_{3}$ & $v_{1}$ & $v_{2}$ & $v_{3}$ & $P_{1}$ & $P_{2}$ & $P_{0}$ \\
\hline (1)' & 1.722 & & 1 & -1 & 0 & 0 & & -1.421 & & & -1.548 & 1.548 \\
\hline (2) & & & 1.859 & & 0 & 0 & 0.680 & & & 1 & & -1 \\
\hline (3)' & & -1.320 & & 1.870 & 0 & 0 & & & 1.449 & & & \\
\hline$(4)^{\prime}$ & & & & & 1 & & & 1.421 & & & 1.548 & -1.548 \\
\hline$(5)^{\prime}$ & & 1.320 & & & & 1 & & & & & & \begin{tabular}{|l|} 
\\
\end{tabular} \\
\hline
\end{tabular}

Table 7 Step 6 for generating $\boldsymbol{G}$

\begin{tabular}{|c|c|c|c|c|c|c|c|c|c|c|c|c|}
\cline { 2 - 13 } \multicolumn{1}{c|}{} & $\mathrm{d} \times / \mathrm{d} t$ & $x(t)$ & \multicolumn{3}{c|}{$z(t)$} & \multicolumn{6}{c|}{$u(t)$} \\
\cline { 2 - 13 } \multicolumn{1}{c|}{} & $\mathrm{d} L_{1} / \mathrm{d} t$ & $L_{1}$ & $F_{1}$ & $F_{3}$ & $F_{2}$ & $P_{3}$ & $V_{1}$ & $V_{2}$ & $V_{3}$ & $P_{1}$ & $P_{2}$ & $P_{0}$ \\
\hline$(1)^{\prime}$ & 1 & & 1 & 1 & 0 & & & 1 & & & 1 & 1 \\
\hline$(2)$ & & & 1 & & & & 1 & & & 1 & & 1 \\
\hline$(3)^{\prime}$ & & 1 & & 1 & & 0 & & & 1 & & & \\
\hline$(4)^{\prime}$ & & & & & 1 & & & 1 & & & 1 & 1 \\
\hline$(5)^{\prime}$ & & 1 & & & & 1 & & & & & & 1 \\
\hline
\end{tabular}

Table 8 Plant CE matrix $\boldsymbol{G}$

\begin{tabular}{|c|c|c|c|c|c|c|c|c|c|c|c|c|}
\hline & & \multicolumn{11}{|c|}{ Causes } \\
\hline & $G$ & $L$ & $F_{1}$ & $F_{3}$ & $F_{2}$ & $P_{3}$ & $v_{1}$ & $v_{2}$ & $v_{3}$ & $P_{1}$ & $P_{2}$ & $P_{0}$ \\
\hline \multirow{11}{*}{ 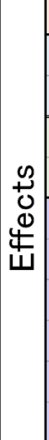 } & $L_{1}$ & 1 & 1 & 1 & & & & 1 & & & 1 & 1 \\
\hline & $F_{1}$ & & 1 & & & & 1 & & & 1 & & 1 \\
\hline & $F_{3}$ & 1 & & 1 & & & & & 1 & & & \\
\hline & $F_{2}$ & & & & 0 & . & & 1 & & & 1 & 1 \\
\hline & $P_{3}$ & 1 & & & & 0 & & & & & & 1 \\
\hline & $v_{1}$ & & & & & & 1 & & & & & \\
\hline & $v_{2}$ & & & & & & & 1 & & & & \\
\hline & $v_{3}$ & & & & & & & & 1 & & & \\
\hline & $P_{1}$ & & & & & & & & & 1 & & \\
\hline & $\rho_{2}$ & & & & & & & & & & 1 & \\
\hline & $P_{0}$ & & & & & & & & & & & 1 \\
\hline
\end{tabular}

three boxed matrices in Table 4. Equations (4) and (5) are converted into (4)' and (5)', respectively. The elements of $F_{2}$ and $P_{3}$ in Eqs. (1) and (3) are swept out by Eqs. (4)' and (5)', as shown in Table 5. The result is shown in Table 6.

Step 6: All elements without "0" in Table 6 are modified to " 1 ," as shown in Table 7.

Step 7: The column of $\mathrm{d} L_{1} / \mathrm{d} t$ is added as Boolean to the column of $L_{1}$, and then deleted. The elements of unmea- 
Table $9 \boldsymbol{R}$ and preference index

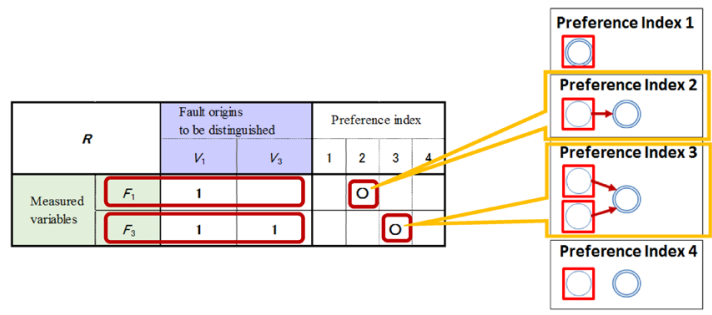

Table $10 A_{1}$ for $V_{1}-F_{1}$

\begin{tabular}{|c|c|c|c|c|c|c|c|c|c|c|c|}
\hline$A_{1}$ & $L_{1}$ & $F_{1}$ & $F_{3}$ & $F_{2}$ & $P_{3}$ & $V_{1}$ & $V_{2}$ & $V_{3}$ & $P_{1}$ & $P_{2}$ & $P_{0}$ \\
\hline$L_{1}$ & $\mathbf{1}$ & & & & & & & & & & \\
\hline$F_{1}$ & & $\mathbf{0}$ & & & & & & & & & \\
\hline$F_{3}$ & & & $\mathbf{1}$ & & & & & & & & \\
\hline$F_{2}$ & & & & $\mathbf{1}$ & & & & & & & \\
\hline$P_{3}$ & & & & & $\mathbf{1}$ & & & & & & \\
\hline$V_{1}$ & & $\mathbf{1}$ & & & & 1 & & & & & \\
\hline$V_{2}$ & & & & & & & 1 & & & \\
\hline$V_{3}$ & & & & & & & & $\mathbf{1}$ & & \\
\hline$P_{1}$ & & & & & & & & & $\mathbf{1}$ & \\
\hline$P_{2}$ & & & & & & & & & & $\mathbf{1}$ \\
\hline$P_{0}$ & & & & & & & & & & 1 \\
\hline
\end{tabular}

sured variables $\left(F_{2}\right.$ and $\left.P_{3}\right)$ of Eqs. (4)' and (5)' are modified to " 0 ." The rows corresponding to $u$ are added to the matrix. The submatrix corresponding to $u$ is modified to a unit matrix. The matrix then becomes a square matrix. Equations (1)'-(5)' are modified to $L_{1}, F_{1}, F_{3}, F_{2}$, and $P_{3}$, and then, the rows and columns of the square matrix correspond to the same variables. This is a CE matrix $\mathbf{G}$ that explains the plant model, as shown in Table 8.

The CE matrices have elements "0" or " 1 ." The blank element indicates "0" elements, too. Column variables and row variables correspond to causes and effects, respectively. When the $(i, j)$ element of the CE matrices is 1 , the $j$-th column variable affects the $i$-th row variable. The 1 at the $\left(F_{1}\right.$, $V_{1}$ ) element of Table 7 shows that the fault origin $V_{1}$ affects the measured variable $F_{1}$.

\subsection{Alarm source variable selection using CE matrices and preference index}

Preference index 1: A measured variable is also a fault origin.

Preference index 2: A measured variable can be reached from one fault origin.

Preference index 3: A measured variable can be reached from two or more fault origins.

Preference index 4: A measured variable cannot be reached from any fault origins.

The submatrix of the reachability matrix of $\boldsymbol{G}$ is called $\boldsymbol{R}$ in the present paper. The rows and columns of $\boldsymbol{R}$ respectively correspond to measured variables and fault origins to be distinguished, as shown in Table 9.
Table $11 G A_{1}$

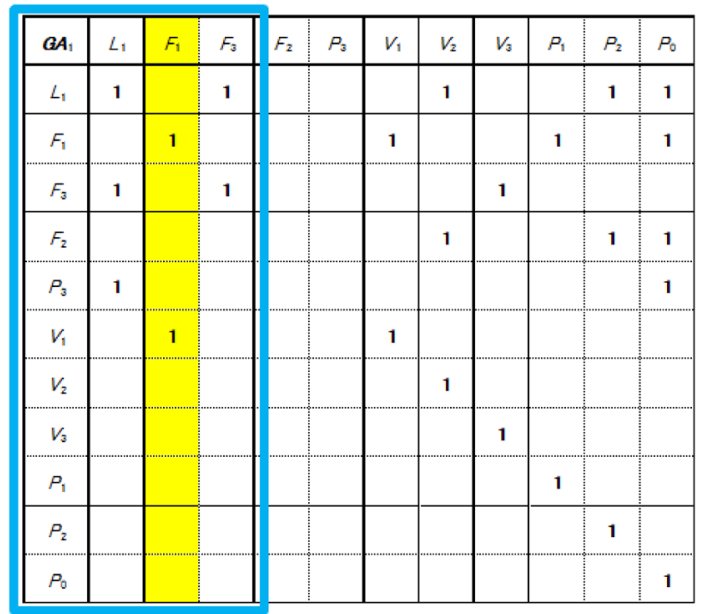

Table $12 R^{\prime}$ based on $A_{1}$ and preference index

\begin{tabular}{|c|c|c|c|c|c|c|c|}
\hline \multirow{2}{*}{$R^{\prime}$ based on $A_{1}$} & \multicolumn{3}{|l|}{$\begin{array}{l}\text { Fault origins } \\
\text { to be distinguished }\end{array}$} & \multicolumn{3}{|c|}{ Preference index } \\
\cline { 2 - 9 } & $V_{1}$ & $V_{3}$ & 1 & 2 & 3 & 4 \\
\hline \multirow{2}{*}{$\begin{array}{l}\text { Measured } \\
\text { variables }\end{array}$} & $F_{1}$ & 1 & & & 0 & & \\
\cline { 2 - 10 } & $F_{3}$ & 0 & 1 & & 0 & & \\
\hline
\end{tabular}

The effect of fault origin $V_{1}$ arrives at the measured variables at $F_{1}$ and $F_{3}$. The effect of fault origin $V_{3}$ arrives at the measured variables at $F_{3}$. Therefore, the preference indices of $F_{1}$ and $F_{3}$ are 2 and 3 , respectively. The number of fault origins that can affect the measured variables may be different. If the distinguishability of measured variable sets is equal, fewer fault origins that can affect the sets are preferred. Only one preference index is added to a measured variable from the preference indices 1 to 4 using the reachability matrix of $G$.

We propose the following usage of the preference index for designing an alarm system. First, a measured variable that has preference index 1 should be selected for an alarm source variable. In this example, none of the measured variables have preference index 1 . Next, a measured variable that has preference index 2 should be selected for an alarm source variable. In this example, the preference index of fault origin $V_{1}$ is index 2 , so the fault origin $V_{1}$ is paired with $F_{1}$. The alarm configuration matrix $A_{1}$ explains the alarm configuration between the fault origin $V_{1}$ and alarm source variable $F_{1}$. Therefore, the element of $\left(V_{1}, F_{1}\right)$ is " 1 ," that of $\left(F_{1}, F_{1}\right)$ is " 0 ," and all other diagonal elements are " 1 ," as shown in Table 10. $V_{1}$ does not affect the lower stream of $F_{1}$ because matrix $A_{1}$ is used.

An alarm loop matrix $\boldsymbol{G A}_{1}$ is calculated by the Boolean multiplication of two matrices, $\boldsymbol{G}$ and $\boldsymbol{A}_{1}$. An alarm loop matrix $\boldsymbol{G} \boldsymbol{A}_{1}$ based on $\boldsymbol{A}_{1}$ is shown in Table 11. The column of $F_{1}$ is changed from $G$ in Table 8 .

The submatrix of the reachability matrix of $\boldsymbol{G} \boldsymbol{A}_{1}$ is called $\boldsymbol{R}$, as shown in Table 12. By using $\boldsymbol{A}_{1}$, the effect of fault 
Table $13 A_{2}$ for $V_{1}-F_{1}$ and $V_{3}-F_{3}$



origin $V_{1}$ does not reach the measured variables at $F_{3}$. Therefore, the preference index of $F_{3}$ is modified to index 2 .

As a result, the measured variable $F_{3}$ is selected as an alarm source variable for $V_{3}$. The alarm configuration matrix $A_{2}$ is shown in Table 13.

\section{Conclusion}

In the present paper, we proposed a sequential method for designing alarm systems using DAEs, CE matrices, and preference indices. Even if a plant is designed properly for the preliminary conditions, plant operation conditions might be changed. The result of change might cause the check points for an alarm system to change. The PHA and $\mathrm{CE}$ matrices can be regenerated from DAEs, so the difficulty of management of change should be easier.

Our design method is the first step to bridging the discontinuity between plant alarm system design and alarm management.

\section{Acknowledgement}

This work was supported by JSPS KAKENHI Grant Numbers 24310119 and 25282101 and the Japan Society of the Promotion of Science (JSPS) 143rd committee on Process Systems Engineering.

\section{Nomenclature}

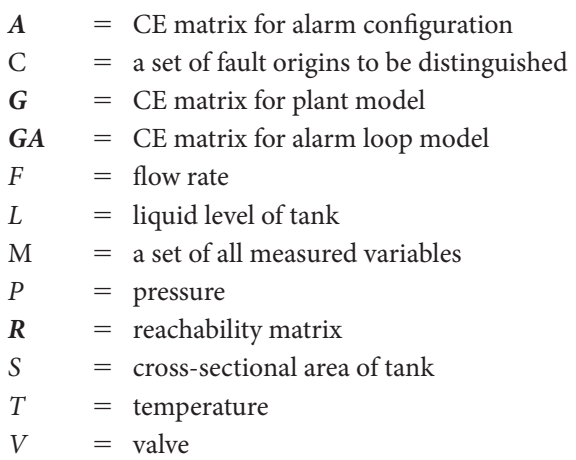

\section{Literature Cited}

The Center for Chemical Process Safety (CCPS); Guidelines for Safe Automation of Chemical Processes, American Institute of Chemical Engineers and John Wiley \& Sons, New York, U.S.A. (1993)

Hamaguchi, T., B. Mondori, K. Takeda, N. Kimura and M. Noda; "A Method of Designing Plant Alarm Systems with Hierarchical Cause-Effect Model," Proceeding of the 11th International Symposium on Process Systems Engineering, pp. 265-269, Singapore, Singapore (2012)

Hamaguchi, T., B. Mondori, K. Takeda, N. Kimura and M. Noda; "Generating Alternative Modules for a Plant Alarm System Based on First-Out Alarm Alternative Signals," Procedia Comput. Sci., 22, 937-944 (2013)

Hamaguchi, T., B. Mondori, K. Takeda, N. Kimura and M. Noda; "A Method for Generation and Check of Alarm Configurations Using Cause-Effect Matrices for Plant Alarm System Design," Proceedings of HIMI 2015, Part II, LNCS 9173, pp. 549-556, Los Angeles, U.S.A. (2015)

IEC; "62682 Ed.1.0: Management of Alarm Systems for the Process Industries," International Electrotechnical Commissions, Geneva, Switzerland (2014)

Iri, M., K. Aoki, E. O'Shima and H. Matsuyama; "An Algorithm for Diagnosis of System Failures in the Chemical Process," Comput. Chem. Eng., 3, 489-493 (1979)

International Society of Automation; Management of Alarm System for the Process Industries, International Society of Automation, Research, Triangl Park, U.S.A. (2009)

Kojima, M., K. Watanabe, H. Moritani, J. Sun, T. Hamaguchi and Y. Hashimoto; "Development of CAD for Plant-Wide Control Loop Configuration," Proceedings of the 5th International Symposium on Advanced Control of Industrial Processes (ADCONIP) pp. 450-454, Hiroshima, Japan (2014)

Moritani, H., S. Yogo, T. Morita, M. Kojima, K. Watanabe, J. Sun, I. Koshijima and Y. Hashimoto; "Development of CAD for Zone Dividing of Process Control Networks to Improve Cyber Security," Proceedings of 14th International Conference on Control, Automation and Systems (ICCAS 2014) pp. 1311-1316, Goyang, Korea (2014)

Moritani, H., T. Yamamoto, S. Yamamoto, K. Ito, J. Sun, T. Hamaguchi, I. Koshijima and Y. Hashimoto; "Generation of Fault Trees for ICS Safety and Security," Proceedings of the 7th International Symposium on Design, Operation, and Control of Chemical Processes (PSE ASIA), p. 102, Tokyo, Japan (2016)

Shiozaki, J., H. Matsuyama, E. O’Shima and M. Iri; "An Improved Algorithm for Diagnosis of System Failures in the Chemical Process," Comput. Chem. Eng., 9, 285-293 (1985)

Takeda, K., T. Hamaguchi and M. Noda; "Plant Alarm System Design based on Cause-Effect Model," Kagaku Kogaku Ronbunshu, 36, 136-142 (2010)

Takeda, K., T. Hamaguchi, N. Kimura and M. Noda; "A Design Method of a Plant Alarm System for First Alarm Alternative Signals Using a Modularized CE Model," Process Saf. Environ. Prot., 92, 406-411 (2014)

Takeda, K., T. Hamaguchi, N. Kimura and M. Noda; "Modelling of a Business Process for Alarm Management Lifecycle in Chemical Industries," Proceedings of HIMI 2015, Part II, LNCS 9173, pp. 597-598, Los Angeles, U.S.A. (2015a)

Takeda, K., T. Hamaguchi, N. Kimura and M. Noda; "Business Process Model Approach for Management of Plant Alarm System," J. Chem. Eng. Japan, 48, 641-645 (2015b) 